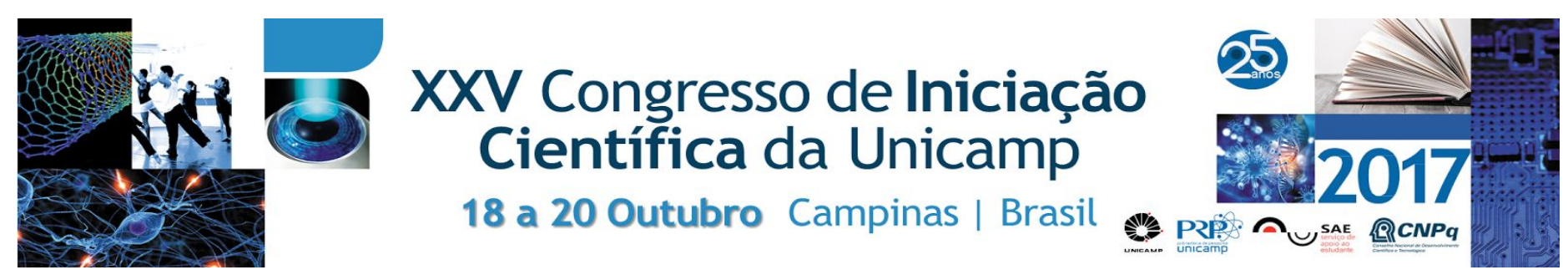

\title{
ELABORAÇÃO E AVALIAÇÃO DE ORGANOGÉIS DE ÓLEO DE GIRASSOL ALTO OLEICO ESTRUTURADOS COM CERA DE CANDELILLA E MONOGLICERÍDIOS.
}

\author{
Bianca C. Borsari, Julia C. Zuin, Daniel Barrera Arellano
}

\begin{abstract}
Resumo
Lipídios exercem uma grande influência nas propriedades sensoriais e físicas dos alimentos, porém o consumo excessivo de ácidos graxos saturados e trans, pode acarretar diversos efeitos negativos para a saúde. Os organogéis tem se apresentado como uma alternativa para a estruturação de óleos em produtos alimentícios, obtendo-se assim, produtos livres de gorduras trans e com teores reduzidos de saturados. Esse estudo tem como objetivo elaborar e avaliar a estrutura e estabilidade de organogéis formulados a partir de óleo de girassol alto oleico.
\end{abstract}

\section{Palavras-chave:}

Organogéis, cera de candelilla, monoglicerídios.

\section{Introdução}

Estudos indicam que o consumo excessivo de gorduras trans e saturadas tem gerado inúmeros problemas de saúde, principalmente cardiovasculares, os quais podem ser reduzidos com sua substituição por óleos mono e poli-insaturadas nos alimentos. Porém, a substituição simples por óleos puros não fornece a textura e propriedades físicas desejadas aos produtos finais. Como alternativa, surgem os organogéis, óleos comestíveis estruturados na forma de redes tridimensionais (SIRAJ et al., 2015; ROGERS, 2009). Dentre as alternativas atuais para obtenção de organogéis com qualidade alimentar, os monoglicerídios e a cera de candelilla são estruturantes com grande potencial, por serem disponíveis e aprovados pela legislação brasileira e mundial para uso alimentício (MICHEL; SAGALOWICZ, 2008; ANVISA, 2005; FDA, 2015).

Neste estudo foram formulados organogéis de óleo de girassol alto oleico estruturado puramente com cera de candelilla (CC) e com monoglicerídios (MG), assim como misturas igualitárias CC-MG, em concentrações totais de estruturantes de 1, 2, 3 e $4 \%$, os quais foram avaliados em consistência (compressão/extrusão), microestrutura e estabilidade.

\section{Resultados e Discussão}

As análises microscópicas dos organogéis mostram que a quantidade de cristais está diretamente relacionada com a força, em Newtons, do gel analisado por um texturômetro na avaliação de consistência. Da mesma forma, os dados mostrados na Tabela 1, indicam um organogel mais forte e mais estável, classificado numa escala de 1 a 5 , de líquido viscoso (1) a um gel totalmente firme (5).

Os organogéis estruturados em CC foram mais estáveis e até 6 vezes mais consistentes que os preparados com MG e que as misturas CC-MG. A microestrutura e a rede cristalina dos organogéis de CC são mais densas que nos de MG e das misturas CC-MG.

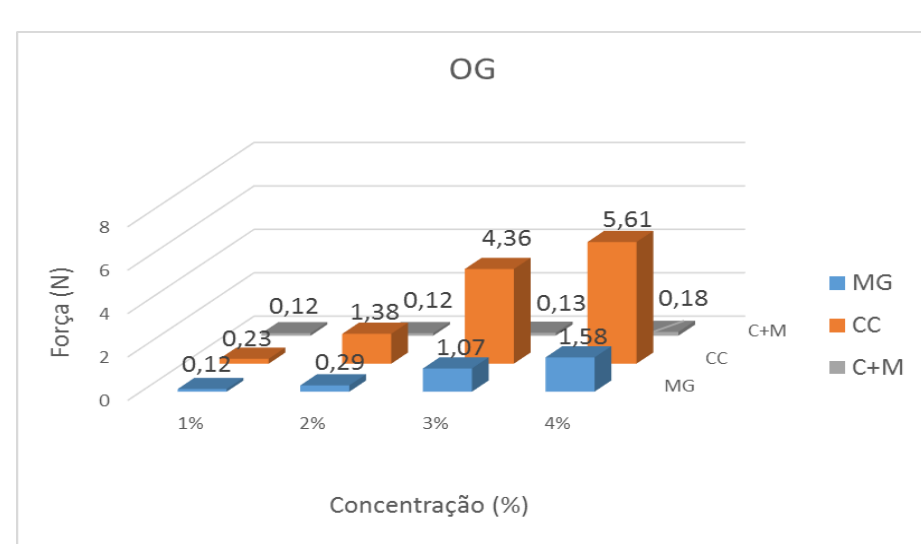

Figura 1. Desempenho dos diferentes estruturantes.

Tabela 1. Consistência e estabilidade dos organogéis.

\begin{tabular}{|c|c|c|c|c|c|c|c|c|}
\hline & \multicolumn{2}{|c|}{$1 \%$} & \multicolumn{2}{|c|}{$2 \%$} & \multicolumn{2}{|c|}{$3 \%$} & \multicolumn{2}{|c|}{$4 \%$} \\
\hline & Força $(\mathrm{N})$ & Estabilid & Força $(\mathrm{N})$ & Estabilida & Força (N) & Estabilide & Força (N) & Estabilidade \\
\hline MAG & 0,1233 & 1 & 0,29 & 3 & 1,07 & 4 & 1,58 & 4 \\
\hline$C C$ & 0,2267 & 2 & 1,3667 & 4 & 4,2633 & 4 & 5,6067 & 5 \\
\hline$C+M$ & 0,115 & 1 & 0,12 & 2 & 0,1333 & 3 & 0,1767 & 4 \\
\hline
\end{tabular}

\section{Conclusões}

Observa-se que a CC apresenta uma capacidade de estruturação de organogéis muito superior à dos MG. A adição de MG produz um efeito negativo na capacidade de estruturação de $\mathrm{CC}$, quando utilizados simultaneamente, monstrando que a CC apresenta-se como melhor estruturante dentre os estudados, com grande potencial para aplicação em produtos alimentícios.

ANVISA. Agência Nacional de Vigilância Sanitária.RDC nº 23, 2005.

FDA, U.S. Food and Drug Administration. CFR 21, v.3, Seção 184.976; 2015. Michel, M.; SAGALOWICZ, L. Probing Food Structure. Food Material Science: Principles and Practices. New York, 2008

Rogers, M.A. Novel structuring strategies for unsaturated fats. Meeting the zero-trans, zero saturated fat challenge: A review. Food Research International, 2009.

SIRAJ, N.; et al. Organogelators as a Saturated Fat Replacer for Structuing Edible Oils. Internarional Journal of Food Properties, v.18, 2015. 